\title{
Modeling of Exhaust-Gas After-Treatment
}

\author{
Olaf Deutschmann $^{1} \cdot$ Daniel Chatterjee $^{2}$
}

Published online: 4 November 2017

(C) Springer International Publishing AG 2017

This special issue of the International Journal of Emission Control Science and Technology presents a selection of the best papers given at the 5th International Symposium on Modeling of Exhaust-Gas After-Treatment (MODEGAT V) held in Bad Herrenalb/Karlsruhe, Germany, on September $3-5,2017$.

The purpose of this biannual symposium is to support the exchange of state-of-the-art modeling and simulation techniques and new approaches among researchers, scientists, and engineers from industry and academia. The location, program, and low conference fee is set up to boost open discussions and new collaborations. Therefore, the number of attendees is limited to 100; as always, a good mix from participants was reached, this time $55 \%$ were from industry.

In total, 56 contributions were presented at MODEGAT V in oral and poster presentations in subsequent sessions, each of them focusing on a special exhaust-gas after-treatment system and reaching from three-way catalysts (TWC), oxidation catalysts (DOC), selective catalytic-reduction ( $\mathrm{SCR}$ ), $\mathrm{NO}_{\mathrm{x}}$ storage catalysts (NSC), and particulate filters (DPF) to after-treatment systems. Individual topics were introduced by keynote lectures, which also served as tutorials for newcomers in the field. We wish to express our appreciation to those keynote speakers: A. Yezerets (Cummins Inc., USA) on SCR, G. Groppi (Politecnico di Milano, Italy) on $\mathrm{CH}_{4}$

Olaf Deutschmann

deutschmann@kit.edu

$\triangle$ Daniel Chatterjee

Daniel.Chatterjee@mtu-online.com

1 Chair Chemical Technology at Karlsruhe Institute of Technology, 76128 Karlsruhe, Germany

2 MTU Friedrichshafen GmbH, 88045 Friedrichshafen, Germany oxidation, M. Votsmeier (Umicore, Germany) on TWC, and W. P. Partridge Jr. (Oak Ridge National Laboratory, USA) on the spatial resolution of reactions inside honeycomb monoliths.

Tremendous reduction of hydrocarbons, carbon monoxide, nitric oxides, and particulates emitted from internal combustion engines is today achieved by the application of automotive catalytic converters and particulate filters, respectively. The systems commonly consist of monolithic structures of many parallel channels, each of which is coated with a porous catalytic active material or the porous walls serve as filter. The zcatalysts, commonly very expensive noble metals such as platinum, palladium, and rhodium, guarantee high conversion but also significantly contribute to high production costs of the automobile exhaust-gas after-treatment system; those costs are meanwhile on the order of the costs of the engine itself. Reduction of the amount of noble metal content without scarifying performance as well as overall optimization of the design and operational conditions of the exhaust-gas aftertreatment system demand a detailed understanding of the complex processes in the converter under varying inlet conditions, i.e., exhaust-gas compositions, flow rate, and temperature. Design and optimization of a catalytic converter is challenging due to the complex interaction between chemical reactions and mass and heat transfer. Experimental test bench measurements are finally needed but they also are expensive and time-consuming and, therefore, should be limited. Furthermore, those experiments are difficult to be interpreted concerning the details of the different chemical and physical processes inside the catalytic structure. Therefore, reliable models and numerical simulations can serve as a powerful method to investigate and eventually optimize the performance of emission control devices. The models and simulations tools, however, can only be of practical relevance if they are developed in close collaboration with the technical 
applications and constraints. Therefore, we believe that novel and original ideas can be boosted by open scientific and technological discussions among academia and industry. The papers presented in this special issue successfully combine fundamental catalysis research and technology to support the development of advanced exhaust-gas after-treatment systems for the hundreds of millions of automotive vehicles present in today's and future world.

Special thanks to Yvonne Dedecek, Ursula Schwald, Martin Spoo (all Karlsruhe Institute of Technology, Germany), and Uwe Riedel (Steinbeis $\mathrm{GmbH} \& \mathrm{Co}$. KG für Technologietransfer, Germany) for their support in the organization of this symposium. Financial support by the DFG funded SFB/TRR 150 "Turbulent, chemically reactive, multi-phase flows near walls" is gratefully acknowledged. Many thanks to those who submitted their work to this special issue. We also want to express our gratitude to all reviewers who provided thoughtful and timely comments. Also, thanks to Sofia Costa from Springer for her help in coordinating the publication process and to the editors of the journal, M. Masoudi and A. Konstandopoulos, for their support of this special issue.

Compliance with Ethical Standards The authors declare that they have no competing interests. 